\title{
A POSIÇÃO DOS SUJEITOS PRÉ-VERBAIS NO PORTUGUÊS BRASILEIRO E NO PORTUGUÊS EUROPEU: IMPLICAÇÕES DA NATUREZA DE AGR *
}

\section{Cláudia Roberta Tavares Silva **}

Resumo: Este artigo, fundamentado no modelo teórico de Princípios e Parâmetros, tem como objetivo precípuo discutir a correlação da posição dos sujeitos em contextos declarativos finitos no português brasileiro (PB) e no português europeu (PE) com a natureza de AGR que está intrinsecamente relacionada ao Parâmetro do Sujeito Nulo. Será argumentado que o enfraquecimento de AGR no PB tem ocasionado uma reestruturação na gramática dessa língua no que concerne à posição dos sujeitos. Além disso, apresentarei evidências empíricas de que sujeitos pré-verbais, com exceção de construções de tópicos marcados, no PB e no PE estão ocupando a posição-A, Spec, AgrSP e de que ambas as línguas possuem movimento curto de V-para-T, o que implica dizer que a morfologia rica que identifica e licencia sujeitos nulos referenciais não corresponde à morfologia rica que motiva o movimento visível do verbo na sintaxe dessas línguas.

Palavras-chave: parâmetro; natureza de AGR; posição dos sujeitos; movimento do verbo

Introdução

Pesquisas desenvolvidas no âmbito da Sintaxe Gerativa têm evidenciado, a partir de estudos comparativos, que o português brasileiro (doravante PB) e o português europeu (doravante PE) possuem gramáticas distintas (cf. Galves, 1996, Torres Moraes, 1996, Costa e Figueiredo Silva, 2003, etc.).

Agradeço aos professores João Costa (UNL) e Maria Denilda Moura (Ufal), e a Jair Gomes de Farias (Ufal), pelos comentários e sugestões. Esta pesquisa foi financiada por uma bolsa da CAPES durante a realização do doutorado no Brasil e do doutorado sanduíche na Universidade Nova de Lisboa ( $n^{0}$ do processo: BEX 0491/ 03-9)

* Doutora pelo Programa de Pós-Graduação em Letras e Lingüística da Universidade Federal de Alagoas. 
Tem sido assumido que um dos mbar de variação paramétrica atestado entre as línguas naturais reside na maneira como os constituintes estão ordenados nas frases (cf. Ouhalla, 1991, mbar, 1992, Costa, 1998, 2000, dentre outros). Observando, por exemplo, a posição dos sujeitos em relação ao verbo no PB e no PE, é possível dizer que, embora sejam línguas cuja ordem não-marcada é $\mathrm{S}$ (ujeito)V(erbo)O(bjeto), elas possuem um comportamento distinto no que se refere à legitimação de sujeitos pós-verbais; enquanto o PB produz apenas as ordens SVO e OSV (cf. (1)), o PE permite cinco ordenações: SVO, OSV, VOS, VSO e OVS (cf. (2)) ${ }^{1}$ :

(1) a. O Paulo comeu a sopa.

b. A sopa, o Paulo comeu.

c. *Comeu a sopa o Paulo².

d. *Comeu o Paulo a sopa.

e. *A sopa, comeu o Paulo.

(2) a. O Paulo comeu a sopa.

b. A sopa, o Paulo comeu.

c. Comeu a sopa o Paulo.

d. Comeu o Paulo a sopa.

e. A sopa, comeu o Paulo.

Costa (2000), ao analisar os contextos declarativos em (2), assume que a variação da ordem de palavras no PE é apenas aparente, haja vista que cada ordem codifica uma estrutura informacional distinta. Nessa acepção, a frase em $\left(2^{\mathrm{a}}\right)$ só é possível como resposta a uma pergunta em que toda a frase é focalizada $(O$ que é que aconteceu?), ao passo que (2c) e (2e) são respostas legítimas a uma pergunta com sujeito focalizado ( $Q$ uem comeu a sopa?), o que leva o autor a argumentar que os contextos discursivos condicionam a produção de uma dada ordem. Contudo, nas frases em (3) do PB, embora o sujeito seja focalizado na pergunta, sua posição na resposta sempre será pré-verbal:

As frases do PE foram extraídas de Costa (2000, p. 2).

2 O uso do asterisco indica que a frase é agramatical. 
(3) A - Quem comeu o bolo?

B - a. O bolo, o João comeu.

b. O João comeu (o bolo).

c. *Comeu o bolo o João.

d. *O bolo, comeu o João.

Embora assuma com Costa $(1998,2000)$ que a variação entre as ordens de palavras no PE não consiste em opcionalidade, defendo que essa variação não decorre de requerimentos de ordem discursiva, mas dos outputs gerados pela sintaxe dessa língua (cf. Costa, 2004) que ganham suporte explicativo no Parâmetro do Sujeito Nulo. Assim, já que no PE sujeitos nulos referenciais são licenciados e identificados pela flexão tal como acontece no italiano e no catalão (cf. Rizzi, 1997), a sintaxe dessa língua gera dois outputs: SV e VS, o que implica considerar que os sujeitos podem ocorrer ora em posição préverbal, ora em posição pós-verbal, esta última suscetível a hospedar sujeitos focalizados conforme previsto pela estrutura informacional. Por outro lado, pelo fato de o PB ser uma língua com o $\mathrm{AGR}^{3}$ mais pobre do que o do PE conforme evidenciado pela alta freqüiência do preenchimento da posição sujeito (cf. Duarte, 2000), a sintaxe dessa língua gera um único output: SV, devendo os sujeitos focalizados ocuparem a posição pré-verbal em satisfação às condições impostas por esse output (cf. (3) acima).

Neste artigo argumentarei que o enfraquecimento do paradigma flexional do PB cujo AGR é "pobre" tem causado uma reestruturação na gramática dessa língua no que se refere à ordenação dos constituintes na frase que não é tão flexível se comparada às diversas possibilidades de ordenação na gramática do PE (cf. as frases em (2)), o que implica dizer, conforme já mencionado, que os dois outputs gerados pela sintaxe dessa última língua cujo AGR ainda é "rico"são os triggers das construções com DPs ${ }^{4}$ sujeitos antepostos e

3 Abreviatura de Agreement ("Concordância"). O uso desse termo, neste contexto, em específico, tem a ver com a morfologia de flexão verbal.

4 Abreviatura de Determiner Phrase (Sintagma Determinante). Para maiores detalhes sobre a existência desse sintagma frasal, cf. Abney (1987). 
pospostos ao verbo, ao contrário do PB que só dispõe de sujeitos préverbais, o que assemelha esta língua a línguas como o inglês e o francês.

Em vista do acima exposto, discorrerei na próxima seção sobre o Parâmetro do Sujeito Nulo na gramática do PB e do PE, a fím de mostrar que a alta frequiência de sujeitos nulos referenciais e a produção da inversão sujeito-verbo com todos os tipos de verbo no PE servem de evidência empírica para caracterizar essa língua como uma língua de sujeito nulo "prototípica" como o italiano e o catalão, ao contrário do PB que se caracteriza como uma língua semi-pro-drop ${ }^{5}$, haja vista ter perdido algumas das propriedades das línguas de sujeito nulo.

Sobre o Parâmetro do Sujeito Nulo na gramática do PB e do PE

- Breves incursões sobre a existência do Parâmetro do Sujeito Nulo

Desde a segunda metade do século $\mathrm{XX}$, o enfoque das pesquisas gerativistas tem sido dado à adequação explicativa dos princípios rígidos da Gramática Universal responsáveis pelas propriedades invariantes nas línguas particulares, bem como à explicação dos parâmetros que estabelecem diferenças entre essas línguas. Sob esse enfoque teórico, denominado Modelo de Princípios e Parâmetros, Rizzi (1988, 1997), assumindo que em todas as línguas a posição de sujeito é obrigatória em satisfação ao princípio EPP (Extended Projection Principle), observa que há línguas em que os sujeitos podem ser realizados foneticamente ou não, o que o leva a apresentar argumentos a favor do Parâmetro do Sujeito Nulo (PSN) proposto por Chomsky (1981). Línguas que exigem a realização fonética obrigatória dos sujeitos, por fixarem o valor negativo desse parâmetro, como é o caso do inglês e do francês, são denominadas línguas de sujeito-não-nulo (línguas não-pro-drop), ao passo que línguas que o fixam positivamente, como é o caso do italiano e do catalão, são chamadas línguas de sujeito nulo (línguas pro-drop). Com

5 Conferir também Coelho et al. (2001) apud Costa (2003, p. 35) 
base na distinção entre esses dois tipos de línguas, Rizzi (1997, p. 270-272) lista as seguintes propriedades relativas ao PSN:

a) O italiano (It.) e o catalão (Cat.) permitem sujeitos nulos com interpretação pronominal definida (cf. (4)) e sujeitos nulos com interpretação não-referencial (cf. (5)), ao contrário do francês (Fr.) e do inglês (Ing.):

$$
\begin{aligned}
& \text { (4)a.__ parla. ("Fala.") (It.) } \\
& \text { b. __ parla. ("Fala.") (Cat.) } \\
& \text { c. *_parle ("Fala.") (Fr.) } \\
& \text { d. *_speaks ("Fala.") (Ing.) } \\
& \text { (5) a. __ piove. ("Chove.") (It.) } \\
& \text { a'. * mb piove. } \\
& \text { b. _ plou ("Chove.") (Cat.) } \\
& \text { b'. *Això plou. } \\
& \text { c. *_pleut ("Chove.") (Fr.) } \\
& \text { c'. Il pleut/ ça pleut. } \\
& \text { d. * _ rained ("Choveu.") (Ing.) } \\
& \text { d'. It is raining ("Está chovendo.") }
\end{aligned}
$$

b) $\mathrm{O}$ italiano e catalão permitem que o objeto direto de uma construção passiva possa permanecer na posição de base (cf. (6)) e que o argumento externo de verbos transitivos e intransitivos permaneça em Spec, $\mathrm{VP}^{6}$ (cf. (7)), ao contrário do francês e do inglês:

(6) a. è mbar dato un premio al presidente. (It.)

"Foi dado um prêmio ao presidente."

b. __ ha estat donat un premi al president. (Cat.)

"Foi dado um prêmio ao presidente."

c. * _ a éte donné un prix au président. (Fr.)

"Foi dado um prêmio ao presidente."

"Spec é a abreviatura de Specifier ("Especificador"), ao passo que VP, a abreviatura de Verbal Phrase (Sintagma Verbal). Portanto, Spec, VP = especificador do sintagma verbal. Para maiores detalhes sobre a existencia de Spec, VP nas estruturas frásicas, conferir Koopman e Sportiche (1991). 
d. _ was given a prize to the president. (Ing.)

"Foi dado um prêmio ao presidente."

(7) a. tem telefonato Gianni. (It.)

"Telefonou o João."

b. __ ha telefonat en Joan. (Cat.))

"Telefonou o João."

c. *_a téléphoné Jean. (Fr.)

"Telefonou o João."

d. *_telephoned John."(Ing.)

"Telefonou o João."

c) O italiano e o catalão permitem extração WH- de sujeitos encaixados com complementador visível, ao contrário do francês e do inglês (cf. (8)):

(8) a. Chi credi che telefonerà? (It.)

"Quem achas que telefonará?"

b. Qui creus que telefonará? (Cat.)

"Quem achas que telefonará?"

c. *Qui crois-tu que téléphonera ? (Fr.) "Quem crês tu que telefonará?"

d. *Who do you think that will telephone? (Ing.) "Quem você acha que telefonará?"

d) O italiano e o catalão possuem marcas de concordância sujeitoverbo bastante ricas morfologicamente, ao contrário do francês e do inglês (cf. (9)):

(9) Italiano.: parl-o, parl-i, parl-a, parl-iamo, parl-ate, parl-ano. Catalão.: parl-o, parl-es, parl-a, parl-em, parl-eu, parl-tem Francês: parl, parl-õ, parl-ế

Inglês: speak, speak-s

7 É pertinente esclarecer que o paradigma do francês apresentado corresponde à realização fonológica das pessoas gramaticais, o que implica considerar que a forma parl compreende um sincretismo entre as formas da $1^{\mathrm{a}}$ p. sing., $2^{\mathrm{a}}$ p. sing., $3^{\mathrm{a}}$.p. sing., e $3^{\mathrm{a}} \mathrm{p}$. pl., ao passo que parl-õ e parl-é correspondem à $1^{\mathrm{a}}$ e $2^{\mathrm{a}} \mathrm{p}$. pl., respectivamente. 
Analisando essas propriedades, Rizzi conclui que sujeitos nulos referenciais só são possíveis em línguas como o italiano e o catalão, tendo em vista elas possuírem morfologia flexional de pessoa rica que é capaz de identificar e licenciar esses sujeitos. Evidência adicional é encontrada no hebraico moderno: no paradigma verbal do tempo presente, a morfologia flexional é pobre e sujeitos nulos referenciais não são possíveis (cf. (10)), ao contrário do que ocorre no tempo passado cuja morfologia flexional é rica (cf. (11)):

10. a. 'ani 'oxel banana

"Eu como $(\mathrm{m}, \mathrm{s})$ uma banana."

a'. *__ 'oxel banana.

"Como ( $\mathrm{m}, \mathrm{s})$ uma banana."

11. a. 'ani 'axalti banana

"Eu comi (s. 1p) uma banana."

a'. _ 'axalti banana

"Comi (s, 1p) uma banana."

(Rizzi, 1997, p. 272)

Analisando línguas como o chinês e o japonês que, embora não tenham morfologia flexional rica, possuem sujeitos nulos referenciais, Jaeggli e Safir (1989) propõem a Hipótese da Uniformidade Morfológica formulada nos seguintes termos:

(12)a. Sujeitos nulos são permitidos em todas e somente em línguas com paradigmas flexionais morfologicamente uniformes;

b. Um paradigma flexional $\mathbb{P}$ numa língua $\mathbb{L}$ é morfologicamente uniforme se e somente se $\mathbb{P}$ tem ou formas flexionais não-derivadas, ou apenas formas flexionais derivadas ${ }^{8}$.

8 a) "Null subjects are permitted in all and only languages with morphologically uniform inflectional paradigms";

b) "An inflectional paradigm $\mathbf{P}$ in a language $\mathbf{L}$ is morphologicaly uniform iff $\mathbf{P}$ has either only underived inflectional forms or only derived inflectional forms." 
Com base na hipótese supracitada, em línguas como o italiano e o catalão, sujeitos nulos referenciais são licenciados e identificados pelo fato de o paradigma flexional dessas línguas possuir formas flexionais derivadas no sentido de que cada pessoa possui um morfema que a especifica gramaticalmente (cf. (9) acima)). Já para o chinês e o japonês, a explicação reside no fato de que não há formas flexionais derivadas em virtude de as pessoas do paradigma não serem especificadas gramaticalmente pelos morfemas. Contudo, apresento, a seguir, contra-evidência ${ }^{9}$ a essa hipótese com base no paradigma de flexão verbal do caboverdiano $^{10}$ (cf. (13)) que, embora seja morfologicamente uniforme por ter forma flexional não-derivada em todos os tempos, não permite sujeitos nulos referenciais (cf. (14)). Veja-se a conjugação do verbo kanta "cantar" nessa língua:

\begin{tabular}{|c|c|l|c|}
\hline & Pretérito perfeito & Presente & Pretérito imperfeito \\
\hline 1SG & N kanta & N ta kanta & N ta kantaba \\
\hline 2SG & Bu kanta & Bu ta kanta & Bu ta kantaba \\
\hline 3SG & E kanta & E kanta & E ta kantaba \\
\hline 1PL & Nu kanta & Nu kanta & Nu ta kantaba \\
\hline 2PL & Nhos kanta & Nhos kanta & Nhos ta kantaba \\
\hline 3PL & Es kanta & Es kanta & Es ta kantaba \\
\hline
\end{tabular}

Tabela 1: Paradigmas verbais extraídos de Pratas (2004)

14. a. N sta duenti.

"Eu estou doente."

a'. *pro sta duenti. (Pratas, 2004, p. 4)

Contudo, apesar da impossibilidade de sujeitos nulos referenciais na língua caboverdiana, Pratas (op. cit.) verifica que sujeitos nulos expletivos são obrigatórios nessa língua (cf. (15)), o que me leva a assumir com essa autora que a disponibilidade desses sujeitos não está associada à morfologia flexional rica, ao contrário

9 Pratas (2004), seguindo Huang (1982), assume que no chinês, por exemplo, o sujeito nulo referencial é produzido em virtude de estar relacionado a propriedades de orientação para o discurso.

10 A variedade do caboverdiano estudada é a de Santiago. 
dos sujeitos nulos referenciais que só podem ser licenciados e identificados se há morfologia flexional rica, seguindo a linha de raciocínio de Rizzi $(1988,1997)$ :

15. a. (*EL/*E) Tem txeu kusa ki $\mathrm{N}$ ka podi kumpra.

"Há/Tem muitas coisas que eu não posso comprar." a' $(* E L / * E)$ Txobi txeu.

"Chove muito./ Está chovendo muito." (Pratas, op. cit., p. 5)

Com base na discussão delineada nesta seção, deterei, a seguir, minha atenção na análise do $\mathrm{PB}$ e do $\mathrm{PE}$ face às propriedades do PSN acima listadas. Cumpre dizer que, para a realização dessa análise, uma caracterização da riqueza de AGR em ambas as línguas faz-se necessário num primeiro momento.

Caracterização da riqueza de $A G R$ no $P B$ e no $P E$ e o Parâmetro do Sujeito Nulo: contra-evidência à hipótese da binaridade desse parâmetro

Caracterizar a riqueza de AGR na gramática das línguas naturais tem sido um dos empreendimentos por parte de gerativistas que se debruçam em investigar a interface sintaxe-morfologia, haja vista assumirem que variações morfológicas são as causas de algumas das variações sintáticas. Para realizar a investigação empreendida nesta seção no que concerne à caracterização da riqueza de AGR no PB e no PE, retomo as propostas de Roberts (1993), Galves (2001) e Vikner (1997), valendo dizer, de antemão, que as duas primeiras relacionam a riqueza de AGR à legitimação e identificação de sujeitos nulos referenciais, ao passo que a terceira associa essa riqueza ao movimento do verbo na sintaxe, nomeadamente, o movimento de $\mathrm{V}$ para- $\mathrm{I}^{11}$.

Quanto à proposta de Roberts (1993), o autor assume que AGR numa língua natural pode ser caracterizado por dois tipos de riqueza: a) riqueza formal: no paradigma de flexão verbal não há

11 O núcleo funcional I(nflection "flexão") só será cindido em AgrS (Agreement Subject) e T(ense "Tempo") neste artigo quando necessário. 
forma zero, sendo cada pessoa gramaticalmente especificada pelo morfema que a identifica, e b) riqueza funcional: no paradigma de flexão verbal há, no máximo, um sincretismo e uma forma zero.

Galves (2001) implementa à proposta de Roberts (op. cit.) a noção de que a Gramática Universal dispõe de dois tipos de pessoa: pessoa sintática e pessoa semântica, sendo a primeira característica de uma língua com o AGR fraco, haja vista não haver especificação gramatical de todas as pessoas pelos morfemas nem no singular, nem no plural, existindo apenas a combinação de traços binários relativos à pessoa e ao número. Em se tratando da pessoa semântica, a autora defende que é típica de uma língua com paradigma cujo AGR é rico em virtude de cada pessoa ser gramaticalmente especificada.

Por outro lado, Vikner (1997), ao analisar o movimento de Vpara-I nas línguas naturais, argumenta que a morfologia de flexão rica que motiva esse movimento visível na sintaxe corresponde à morfologia flexional de pessoa presente em todos os tempos verbais.

Portanto, partindo das propostas acima mencionadas, caracterizo, a seguir, a riqueza de AGR no PB e no PE, tomando por base os seguintes paradigmas verbais no presente do indicativo (cf. (16)) e no pretérito perfeito $(\mathrm{cf}(17))^{12}$ :

Tomando por base a proposta de Roberts (op. cit.), observo que, em PB, AGR é formal e funcionalmente "pobre". No primeiro caso, é "pobre" devido à existência de duas formas zero ( $2^{\mathrm{a}} \mathrm{p}$. sing. (tu) e $2^{\mathrm{a}}$ p. pl. (vós)), e, no segundo caso, devido não só à existência de duas formas zero, mas também de dois sincretismos: de um lado, as formas pronominais você, ele(a) e a gente no singular são todas gramaticalmente especificadas pelo morfema $\varnothing$; por outro, as formas de $2^{\mathrm{a}}$ p. pl (vocês) e $3^{\mathrm{a}}$ p. pl. (eles(as)) são gramaticalmente especificadas no presente do indicativo e no pretérito perfeito pelos morfemas $-m$ e -ram, respectivamente. Similar ao PB, no PE, o AGR também é formalmente "pobre" por haver uma forma zero no paradigma $\left(2^{\mathrm{a}} \mathrm{p} . \mathrm{pl}(\right.$ vós $\left.)\right)$, e funcionalmente "pobre" não pela

12 Os paradigmas de flexão verbal foram elaborados partindo de duas realizações dialetais: a) o dialeto falado na cidade de Maceió (PB) e o dialeto falado na cidade de Lisboa (PE). 
existência de uma única forma zero ( $2^{\mathrm{a}} \mathrm{p}$. pl. (vós)), mas por haver no paradigma dois sincretismos que são similares aos do PB.

(16) PRESENTE DO INDICATIVO

\begin{tabular}{|c|c|}
\hline PB & PE \\
\hline Eu canto & Eu canto \\
\hline$--\cdot----$ & Tu cantas \\
\hline Você/ ele(a)/ a gente canta & Você/ ele(a)/ a gente canta \\
\hline Nós cantamos & Nós cantamos \\
\hline$-\cdot-\cdot--\cdot---$ & $-\cdot-\cdot---$ \\
\hline Vocês/ eles(as) cantam & Vocês/ eles(as) cantam \\
\hline
\end{tabular}

(17) PRETÉRITO PERFEITO

\begin{tabular}{|c|c|}
\hline PB & PE \\
\hline Eu cantei & Eu cantei \\
\hline------ & Tu cantaste \\
\hline Você/ ele(a)/ a gente cantou & Você/ ele(a)/ a gente cantou \\
\hline Nós cantamos & Nós cantamos \\
\hline$-\cdot-\cdot-\cdot----\cdot-\cdot-$ \\
\hline Vocês/ eles(as) cantaram & Vocês/ eles(as) cantaram \\
\hline
\end{tabular}

Nesse sentido, é possível estabelecer uma escala de gradação da riqueza de AGR entre as línguas analisadas: no paradigma do $\mathrm{PB}$, o AGR é mais pobre formal e funcionalmente do que no do PE. Formalmente, há duas formas zero no paradigma da primeira língua e apenas uma forma zero no da segunda. Funcionalmente, embora em ambas as línguas haja dois sincretismos no singular e no plural, em $\mathrm{PB}$, o AGR é mais pobre do que o do PE devido à existência de duas formas zero.

Tendo em vista o PE só possuir uma única forma zero no paradigma de flexão verbal relativa à $2^{\mathrm{a}} \mathrm{p}$. pl (vós), implica dizer que, seguindo a análise de Galves (2001), o AGR nessa língua é rico por ser a pessoa semântica, pois no singular as três pessoas são especificadas pelos seus respectivos morfemas, ao passo que no $\mathrm{PB}$ tem-se a pessoa sintática por haver duas formas zero, culminando, portanto, na combinação de traços binários, conforme verificado, por exemplo, no presente do indicativo: [+pessoa, -número]-o, [+pessoa, +número]-mos, [-pessoa, -número]-a, [-pessoa, +número]-m. Em 
suma, o PB evidencia que sua morfologia mais uma vez é fraca em relação à morfologia do $\mathrm{PE}$.

Retomando a proposta de Vikner (1997), posso dizer que não é possível estabelecer uma riqueza distinta entre o AGR do PB e o do $\mathrm{PE}$, tendo em vista que ambas as línguas têm movimento de V-para-I em sentenças declarativas finitas, conseqüência de a morfologia de pessoa estar presente em todos os tempos: Nos paradigmas de (16) e (17), a primeira pessoa do singular é sempre distinta das demais a partir da especificação gramatical fornecida pelos morfemas.

Levando em conta que a presença de advérbios e de quantificadores flutuantes entre o verbo e o objeto é uma das evidências de que uma língua natural tem movimento de V-para-I, Costa e Galves (2002, p. 111) constatam que em PB e PE esse movimento ocorre (cf. (18a) e (18b)), tal como verificou Pollock (1989, p. 367) numa língua como o francês (cf. (19a) e (19b)), ao contrário do inglês (cf. $\left(20^{a}\right)$ e (20b)):

(18) a. O João beija freqüentemente a Maria.

b. Meus amigos amam todos a Maria.

(19) a. Jean embrasse souvent Marie.

"João beija freqüentemente a Maria."

b. Mes amis aiment tous Marie.

"Meus amigos amam todos a Maria."

(20) a. *Jonh kisses often Mary.

"João beija frequentemente a Maria."

b. *My friends love all Mary.

"Meus amigos amam todos a Maria."

Apesar de no PB, no PE e no francês haver movimento de Vpara-I, Costa e Galves (2002, p. 110-111) observam que há um comportamento diferenciado entre essas línguas: nas duas primeiras, o advérbio e o quantificador flutuante podem ocupar uma posição intermediária entre o sujeito e o verbo (cf. $\left(21^{\mathrm{a}}\right)$ e (21b)), ao passo que na terceira essa posição é bloqueada (cf. (22 $2^{\mathrm{a}}$ e e (22b)):

(21) a. João freqüentemente beija a Maria.

b. Meus amigos todos amam a Maria. 

PORTUGUÊS EUROPEU: IMPLICAÇÕES DA NATUREZA DE AGR

(22) a. *Jean souvent embrasse Marie.

"João frequentemente beija a Maria."

b. *Mes amis tous aiment Marie.

"Meus amigos todos amam a Maria."

Com base na assimetria acima, poder-se-ia pensar que a presença do advérbio e do quantificador flutuante ora pré-verbal, ora pós-verbal seria evidência de que o movimento de V-para-I na gramática do $\mathrm{PB}$ e do $\mathrm{PE}$ é opcional, no entanto, Costa e Galves (2002, p. 112) argumentam que esse movimento é obrigatório, haja vista que advérbios com leitura orientada para o sujeito só podem aparecer entre o sujeito e o verbo $\left(\right.$ cf. $23^{\mathrm{a}}$ ), ao contrário de um advérbio com leitura de modo (cf. (23b)).

(23) a. O Pedro inteligentemente leu o livro. (Orientado para o sujeito/*Modo)

b. O Pedro leu inteligentemente o livro. (*Orientado para o sujeito/Modo)

Seguindo a linha de raciocínio dos autores no que concerne à agramaticalidade de advérbios orientados para o sujeito adjuntos ao VP em (23b), assumo com esses autores que sempre há movimento curto de V-para- $\mathrm{T}$ em frases declarativas finitas no $\mathrm{PB}$ e no $\mathrm{PE}$ quer o advérbio esteja adjunto a $\mathrm{TP}^{13}$ (cf. (24)), quer esteja adjunto ao VP (cf. (24b)):

(24) a. O João freqüientemente beija a Maria.

$\mathrm{a}^{\prime}$. [AgrSP $\mathrm{O}$ João ${ }_{\mathrm{i}}\left[{ }_{\mathrm{AgrS}}\left[\mathrm{TP}\right.\right.$ frequentemente $\left[_{\mathrm{TP}} \mathrm{t}_{\mathrm{j}}\left[_{\mathrm{T}}\right.\right.$ beija $\mathrm{a}_{\mathrm{k}}[\mathrm{vP}$ $\mathrm{t}_{\mathrm{i}}\left[\mathrm{v}, \mathrm{t}_{\mathrm{k}}\right.$ a Maria] $\left.\left.]\right]\right]$

b. O João beija freqüentemente a Maria.

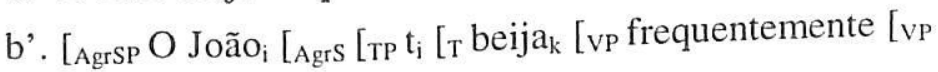
$t_{i}\left[v, t_{k}\right.$ a Maria $\left.\left.\left.]\right]\right]\right]$

Com base nas evidências empíricas acima, sou levada a assumir, ao contrário de Gonçalves (1994), que a morfologia rica que

13 Abreviatura de Tense Phrase ("Sintagma Temporal"). 
licencia e identifica sujeitos nulos referenciais não tem a ver com a morfologia rica que motiva movimento do verbo na sintaxe.

Ademais, conforme ficou evidente a partir da análise dos paradigmas de flexão verbal, ao adotar as propostas de Roberts (1993) e de Galves (2001), o AGR do PB é mais pobre do que o do PE. Partindo dessa constatação, na próxima seção, estabelecerei correlação entre a riqueza de AGR em ambas as línguas e as propriedades do Parâmetro do Sujeito Nulo listadas por Rizzi (1997).

- Sobre as propriedades do Parâmetro do Sujeito Nulo na gramática do PB e do PE

Retomando as propriedades em 2.1 listadas por Rizzi (1997) relativas ao PSN, veja-se, a seguir, como a gramática do PB e do PE comporta-se frente às mesmas:

a) Em PE, a morfologia de flexão verbal licencia e identifica sujeitos nulos referenciais (cf. (25)), em PB, ao contrário, devido ao enfraquecimento de sua morfologia verbal, está havendo um aumento acentuado do preenchimento da posição pré-verbal do sujeito por DPs referenciais realizados foneticamente (cf. (26a) e (26b) $)^{14}$, sendo uma das evidências a duplicação de sujeitos pré-verbais por um pronome co-referente (cf. (27a)-(27b)), uma opção não prevista na gramática do PE. No que concerne aos sujeitos expletivos, ambas as línguas possuem-no (cf. (28)):

(25) a. Comemos o bolo.

b. Eles pensam termos comido o bolo.

(Raposo, 1992, p. 482)

(26) a. Nova Trento $_{i}$ é do tamanho da rua São Clemente de Botafogo. Ela é desse tamanho. Ela não tem paralelas.

b. Você quando você viaja, você passa a ser turista. Então você passa a fazer coisas que você nunca faria no Brasil.

(Duarte, 2000, p. 22-23)

14 Sugiro ao leitor consultar os resultados estatísticos contidos na pesquisa diacrônica realizada por Duarte (2000). 

PORTUGUÊS EUROPEU: IMPLICAÇŌES DA NATUREZA DE AGR

(27) a. A Clarinha $a_{i}$ ela $a_{i}$ cozinha que é uma maravilha. (OKPB ??PE)

b. Eu acho que o povo brasileiro ele $_{i}$ tem uma grave doença. (OKPB *PE)

(28) a. Chove.

a'. *Ele chove.

b) O PE produz inversão sujeito-verbo com verbos que selecionam ou um argumento externo (cf. (29) e (30)), ou um argumento interno (cf. $(31))^{15}$. No PB, essa inversão está restrita a construções com verbos inacusativos que selecionam obrigatoriamente um argumento interno (cf. (32) $)^{16}$. Quanto às construções passivas, o argumento interno pode permanecer na posição de base em ambas as línguas (cf. (33)):

(29) a. O Paulo comeu a sopa.

b. Comeu a sopa o Paulo

c. Comeu o Paulo a sopa.

e. A sopa, comeu o Paulo.

f. A sopa, o Paulo comeu.

(Costa, 2000, p. 2)

(30) Telefonou o Manuel/ um amigo.

(Brito et al., 2003, p. 447)

(31) Chegaram os alunos.

(Fiéis, 2003, p. 156)

(32) a. Chegou o trem.

b. ?Telefonou o cliente.

c. *Assinou uma carta o chefe do departamento.

d. **Enviou uma carta a todos o presidente da associação.

(Kato, 1999, p. 1)

(33) Foi convidado um estudante para a festa.

(Raposo, 1992, p. 483)

15 Cf. também Ambar (1992), Gonçalves (1994), Costa (1998, 2000, 2001), Fiéis (2003), Brito et al. (2003), dentre outros.

16 Cf. também Figueiredo Silva (1996), Berlinck (1988, 2000), Kato (1999), Coelho (2000), Spanó (2002), dentre outros. 
Vale pontuar que no caboverdiano, à semelhança do inglês e do francês, a inversão sujeito-verbo só ocorre em construções inacusativas, sendo o DP pós-verbal necessariamente indefinido. Embora o PB assemelhe-se a essas três línguas pelo fato de a ordem VS estar restrita aos contextos inacusativos, a única diferença entre elas reside no fato de que nestas três últimas línguas, o DP pós-verbal tem de ser indefinido ( $\mathrm{cf}(34)$ ), ao contrário do PB que, à semelhança do PE, possui DPs pós-verbais definidos e indefinidos (cf. (35)), podendo estes serem modificados por quantificadores universais (cf. (36)), o que contraria a proposta de Belletti (1988):

(34) a. (dja) Txiga tres algen.

"(Já) Chegaram três pessoas."

a'. *(dja) Txiga Juau."

"(Já) Chegou o João."

(Pratas, 2004, p. 5)

b. There arrived a man/*the man/*every man.

"Chegou um homem/*o homem/*todo homem."

c. *Il est arrivé un homme/*l'homme.

"Chegou um homem/*o homem."

(Alexiadou e Anagnostopoulou, 1998, p. 512)

(35) a. Chegou o João.

b. Chegou um garoto.

(36) a. “...a gente saía pra dançar nos fins de semana já saía $o$ grupo todo." (PB - I.12.P.27.L.153)

b. Nesse jantar apareceram todos os meus amigos.

(Ambar, 1992, p. 127)

c. Em PE e PB, ocorre extração WH- de sujeitos encaixados:

(37) a. Quem (é que) tu pensas que $t$ viu esse filme?

(Raposo, 1992, p. 483)

b. Quem você acha que $t$ comeu o bolo?

17 Esta frase foi extraída do Banco de Dados do LUAL (Língua Usada em Alagoas) cuja responsável é a professora Maria Denilda Moura. As indicações após a frase indicam, respectivamente, o número do informante entrevistado, a página e a linha de ocorrência da frase no corpus da pesquisa. 
d. O PB possui morfologia flexional mais pobre do que a do PE: na primeira língua, há apenas quatro pessoas gramaticalmente distintas, ao passo que na segunda há cinco distinções de pessoa (cf. os paradigmas em (16) e (17) acima).

Analisando as propriedades do Parâmetro do Sujeito Nulo acima no $\mathrm{PB}$ e no PE, observo que a primeira língua ainda compartilha algumas propriedades sintático-semânticas com a segunda: a) possível legitimação de sujeitos nulos referenciais ainda que com pouca frequiência (cf. Duarte, 2000); b) extração WH- de um sujeito encaixado, c) possibilidade de ocorrência de DPs pós-verbais definidos e indefiniđos em construções inacusativas, ao contrário do que ocorre no inglês, no francês e no caboverdiano e d) possibilidade de o argumento interno nas construções passivas e inacusativas permanecer em sua posição de base. Essas evidências, portanto, levam-me a assumir que o PB é uma língua semi-pro-drop, o que põe em questão a binaridade do Parâmetro do Sujeito Nulo proposta por Rizzi (1988, 1997).

No que concerne especificamente à perda da inversão sujeitoverbo em construções transitivas e intransitivas, salvo aquelas construídas com verbos intransitivos como telefonar e viajar que, segundo pontua Figueiredo Silva (1996), comportam-se de forma similar a um verbo inacusativo ${ }^{18}$, assumo que, no $\mathrm{PB}$, essa inversão é apenas produtiva em construções inacusativas em decorrência do

18 Analisando as frases em (i), Figueiredo e Silva (1996, p. 97) observa que, em (a) e (b), os verbos intransitivos telefonar e viajar, respectivamente, admitem sujeitos invertidos, ao contrário de verbos como tossir e espirrar em (c) e (d), respectivamente, o que leva essa autora à seguinte hipótese: "...parece claro que devemos dizer que os verbos intransitivos do PB têm um comportamento um tanto estranho admitindo que alguns dentre eles se comportem como ergativos.". Nesse sentido, infiro que os contextos residuais da ordem VS com alguns dos verbos intransitivos decorrem das propriedades lexicais destes:

(i) a. Telefonou um cara aí pra você.

b. Viajou uma mulher supergorda do meu lado.

c. *Tossiu/ estava tossindo um cara atrás de mim.

d. *Espirrou/ estava espirrando um cara durante o filme. 
enfraquecimento de AGR nessa língua. Os resultados obtidos por Berlinck (1988, 2000) e Torres Moraes (1996) sobre a ordem VS apontam que essa ordem passa por um decréscimo acentuado com os verbos transitivos nos fins do século XVIII para o início do século XIX, um período que, de certa forma, coincide com a época em que a posição sujeito começa a ser preenchida por sujeitos realizados foneticamente (cf. Duarte, 2000). O período correspondente à segunda metade do século XX, em que é verificada a restrição da ordem VS aos contextos com verbos inacusativos, corresponde também ao período em que há uma alta frequêencia do preenchimento da posição pré-verbal do sujeito. Nos resultados quantitativos de Duarte (op. cit.. p. 19) fica evidente o aumento gradual do preenchimento dessa posição ao longo dos sete períodos da história: 1845 (20\%), 1882 (23\%), 1918 (25\%), 1937 (46\%), 1955 (50\%), $1975(67 \%)$ e 1992 (74\%). Nessa acepção, assumo que, por ser o AGR do PB mais pobre do que o do $\mathrm{PE}$, conforme evidenciado pela impossibilidade de inversão com verbos que selecionam um argumento externo, a sintaxe dessa língua gera um único output: SV, ao contrário do PE que possui dois outputs: SV e VS.

Vale pontuar que a ordem VS atestada no PB e no PE em construções inacusativas corresponde a uma "pseudo-ordem VS" pelo fato de o DP pós-verbal subcategorizado por um verbo inacusativo ser um objeto e não um sujeito (cf. Burzio, 1986). Nesse sentido, verifico que a gramática do PB não produz "verdadeira" ordem VS, haja vista a incapacidade de verbos inacusativos selecionarem um argumento externo, o que implica dizer que a posição Spec, VP não é projetada na estrutura-D (cf. (38a')), mas apenas Spec, $\mathrm{IP}^{19}$, uma posição suscetível para hospedar os argumentos internos desses verbos quando movidos de sua posição de base, conforme representado em (39a'):

(38) a. Chegou uma carta.

a'. [IP $\left[{ }_{1}\right.$ chegou $_{k}\left[{ }_{\text {VP }} t_{k}[\right.$ DP uma carta $\left.\left.\left.]\right]\right]\right]$

(39) a. Uma carta chegou.

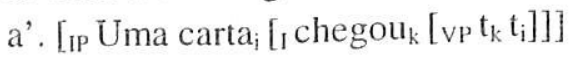

19 Abreviatura de Inflectional Phrase IP ("Sintagma Flexional"). 
Em linhas gerais, com base no que foi dito até o momento, o enfraquecimento da morfologia flexional e o aumento acentuado de DPs referenciais preenchendo a posição pré-verbal de sujeito no PB têm ocasionado a perda da inversão sujeito-verbo nessa língua, o que aponta para o fato de a gramática dessa língua estar passando por um processo de mudança, conforme verificado no seu caráter semi-prodrop. Um fato curioso é que, embora haja um decréscimo acentuado de sujeitos nulos referenciais no $\mathrm{PB}$, sujeitos nulos expletivos continuam produtivos nessa língua à semelhança do $\mathrm{PE}$, o que vem corroborar a análise desenvolvida por Pratas (2004) para o caboverdiano no sentido de que o licenciamento de sujeitos nulos expletivos não tem a ver com morfologia de flexão rica. Ademais, contra-evidência à Hipótese da Uniformidade Morfológica proposta por Jaeggli e Safir (1989) não é só encontrada no caboverdiano, mas também no PB. Na primeira língua, o paradigma é uniforme em todos os tempos, contudo não há sujeitos nulos referenciais, ao passo que, na segunda língua, embora não haja uniformidade morfológica no paradigma flexional nos termos propostos pelos autores, sujeitos nulos referenciais ainda são produzidos, conforme atestam frases como: a) pro Fomos para Maceió ontem.; pro Estou com fome, as quais servem como uma das evidências para caracterizar o PB como uma língua semi-pro-drop.

Por uma análise unificada da posição dos sujeitos pré-verbais no PB e no PE

Nesta seção, partindo da discussão sobre o Parâmetro do Sujeito Nulo na gramática do PB e do PE e sobre a caracterização da riqueza de AGR em ambas as línguas, realizo uma análise sobre a posição dos sujeitos pré-verbais nessas línguas, observando que no PB é forçoso argumentar a favor da análise de que sujeitos pré-verbais nessa língua estão deslocados à esquerda, sendo duplicados por um pronome co-referente nulo ou visível em Spec, TP (cf. Duarte, 2000, Barbosa et al., 2001, Galves, 2001, Costa e Galves, 2002, dentre outros). Ao contrário desses autores, apresentarei evidências que Spec, TP não é uma posição legítima para hospedar sujeitos pré-verbais no PB à semelhança do PE. A seguir, vejam-se as análises propostas para explicar o lugar de pouso dos sujeitos pré-verbais no PE e no PB face às evidências empíricas encontradas. 
Posição dos sujeitos pré-verbais na gramática do PB e do PE Sujeitos pré-verbais no $\mathrm{PE}$ estão ocupando uma posição-A, nomeadamente Spec, $\mathrm{AgrSP}^{20}$, conforme ilustra a seguinte representação (cf. Costa e Galves, 2002, p. 116):

$\left[{ }_{\text {AgrSP }} \operatorname{Suj}\left[\operatorname{TTP}_{\text {Suj }} V\left[\right.\right.\right.$ vp $\left.\left.\left._{\text {Suj }} t_{v}\right]\right]\right]$

Evidências:

A. Ligação-A com sujeitos pré-verbais:

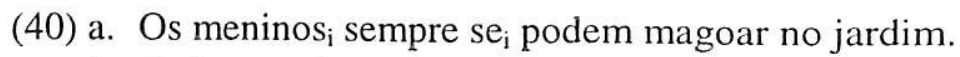

b. Cada menino ${ }_{i}$, nos seus jogos ${ }_{i}$, sempre aprende alguma coisa.

c. *Cada menino, eu vi.

(Brito, 2001, p. 72-73)

Brito, assumindo que sujeitos pré-verbais estão ocupando uma posição-A no $\mathrm{PE}$, apresenta como evidência, além da ligação-A estabelecida em (40a) e (40b), a impossibilidade de topicalização de constituintes quantificados nessa língua (cf. (40c)), o que implica dizer que, em (40b), o DP quantificado Cada menino não está deslocado à esquerda, mas encontra-se numa posição-A.

B. SVO em contexto não-marcado:

(41) A: O que aconteceu?

B: a. O João partiu um copo.

b. *Partiu o João um copo.

(Costa e Galves, 2002, p. 118)

20 Abreviatura de Agreement Subject Projection ("Projeção de concordância associada ao sujeito"). Levando em conta a proposta de Pollock (1989) para a cisão de IP, AgrSP domina TP na estrutura frásica e, portanto, corresponde à posição-A(rgumental) mais alta que o DP sujeito pode ocupar nessa estrutura. 
Em (41), a única resposta legítima à pergunta em que toda a frase é focalizada corresponde à resposta em (41a) com a ordem SVO, o que serve de contra-evidência à análise de Barbosa (1996) que assume Spec, VP como a única posição-A para os sujeitos em PE. Conforme argumentam Costa e Galves, não há motivação para adotar essa hipótese, haja vista a agramaticalidade da frase em (41b) em que o sujeito, embora estando na posição Spec, VP, não pode ocupar essa posição num contexto em que há focalização de toda a frase.

C. Contexto marcado de topicalização múltipla:

(42) a. Sobre o tempo, falei com o Pedro.

b. ?/?? Sobre o tempo, com o Pedro, falei.

(Costa, 1998, p. 112)

De mais a mais, as evidências acima apresentadas por Costa e Galves, levam-me a assumir com Costa (2003) que sujeitos préverbais no PE estão numa posição-A, nomeadamente Spec, AgrSP e não Spec, TP em virtude de não só advérbios com orientação para o sujeito, como estupidamente, estarem adjungidos a TP, mas também de advérbios como sempre, quando adjungidos a TP, romperem a adjacência entre o sujeito pré-verbal e o verbo.

Posição dos sujeitos pré-verbais em PB: contra-evidência ao deslocamento à esquerda

A riqueza morfológica de AGR nos moldes de Roberts (1993) e Galves (2001) tem implicações na gramática do PB e do PE para a posição dos sujeitos em ambas as gramáticas. Por um lado, a legitimação de sujeitos pré-verbais em Spec, AgrSP e de sujeitos pósverbais em Spec, VP no PE é conseqüência de o AGR nessa língua ser mais rico. Por outro lado, observando a posição de advérbios como sempre e intencionalmente que não podem intervir entre o sujeito e o pronome que o duplica, argumento que a única posição-A que pode hospedar os sujeitos pré-verbais em PB é Spec, AgrSP e não Spec,TP, ao contrário da análise de eles estarem deslocados à esquerda, valendo ressaltar que, nas construções de tópicos sujeitos (cf. Galves, 1998) como em (43), inexistente no PE, eles estão adjungidos a AgrSP, uma possível consequiência do enfraquecimento de AGR. Nessas construções, seguindo a análise de Costa e Galves (2002), há 
movimento dos traços- $\Phi^{21}$ do verbo em $\mathrm{T}$ para Agr, conforme ilustrado na representação em (44):

(43) O relógio quebrou o ponteiro.

(44) [AgrSP $\left._{\text {Suji }}\left[{ }_{\mathrm{AgrSP}} \mathrm{AgrS}_{\mathrm{i}}\left[\mathrm{TP}_{\mathrm{TP}} \mathrm{V}-\Phi_{\mathrm{i}}\left[\mathrm{vP}_{\mathrm{v}} \mathrm{t}_{\mathrm{v}} \mathrm{pro}_{\mathrm{i}}\right]\right]\right]\right]$

Evidências empíricas para os tópicos sujeitos não estarem numa posição-A são apresentadas, a seguir:

A. Impossibilidade de advérbios orientados para o sujeito (cf. (44a)) e de um agente implícito como controlador do sujeito das orações finais (cf. (44b)):

(44) a. *O relógio intencionalmente quebrou o ponteiro.

b. *O relógio quebrou o ponteiro para atrasar a viagem do meu pai.

B. Impossibilidade de ligação-A:

(45) *O relógio ${ }_{i}$ quebrou o $\mathrm{seu}_{\mathrm{i}}$ ponteiro.

Ao contrário do que ocorre nas construções de tópicos sujeitos, nas estruturas frásicas que se seguem, é plausível argumentar que os sujeitos pré-verbais no PB também ocupam uma posição-A, conforme evidenciam alguns dos diagnósticos que se seguem:

A. Ligação-A com sujeitos pré-verbais:

(46) Minha amiga $a_{i}$ acha que ela $a_{i}$ encontrará um emprego.

(Silva, 2004, p. 422)

B. Bloqueio de expressão quantificada topicalizada:

(47) a. Cada criança $\mathrm{a}_{\mathrm{i}}$, durante suas férias, gosta de viajar.

b. * Cada criança, eu vi.

(Silva, loc. cit.)

21 Aos traços- $\Phi$ correspondem os traços gramaticais da flexão verbal associados a pessoa, número e gênero. 
C. Contexto marcado de topicalização múltipla:

(48) a. Sobre a viagem, falei com meu esposo.

b. ?/?? Sobre a viagem, com meu esposo, falei.

(Ibid., p. 423)

D. Ausência de efeitos de minimalidade A-barra:

(49) a. Perguntei quem o Pedro tinha encontrado.

b.??*Perguntei quem ao Pedro tinha oferecido o presente.

(Silva, loc.cit.)

Ao se deter à análise dos sujeitos pré-verbais no $\mathrm{PB}$ e, verificando que a presença de ligação-A e a ausência de efeitos de minimalidade estão presentes nessa língua, Brito (2001) argumenta que esses sujeitos encontram-se numa posição-A ora em Spec, AgrSP, ora em Spec, TP. A possibilidade dessas duas posições estruturais para os sujeitos, segundo a autora, está relacionada com a posição do advérbio sempre. Assumindo que o movimento do verbo na gramática do PB é curto e de que esse advérbio pode adjungir-se ao VP ou a TP, Brito verifica que o sujeito encontra-se em Spec, AgrSP quando o advérbio está adjungido a TP, caso contrário, estando adjungido ao VP, o sujeito está em Spec, TP, conforme ilustram as configurações sintáticas em (50a') e (51a'), respectivamente:

(50) a. O João sempre compra os pães.

$a^{\prime}$. [AgrSP O João ${ }_{i}{ }_{T P}$ sempre $\left[{ }_{T P} t_{i}\left[T\right.\right.$, compra $_{j}\left[v_{p} t_{i}\left[v^{\prime} t_{j}\right.\right.$ os pães]]]]]]

(51) a. O João compra sempre os pães.

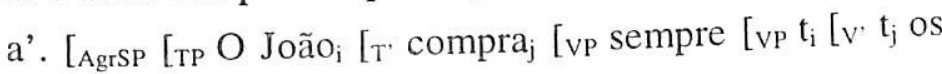
pães]]]]]]

Embora argumente nesta artigo que sujeitos pré-verbais ocupem uma posição-A no PB, à semelhança de Brito (2001), distancio-me em parte de sua análise por assumir que Spec, AgrSP é a única posição-A legítima para hospedar esses sujeitos, tomando por base as seguintes evidências: 
a) Advérbios com leitura orientada para o sujeito, por estarem adjungidos a TP, rompem a adjacência entre o sujeito pré-verbal e o verbo:

(52) a O João atenciosamente fez sua tarefa. (leitura orientada para o sujeito/ *leitura de modo)

b. O João fez atenciosamente sua tarefa. (*leitura orientada para o sujeito/ leitura de modo)

(Silva, 2004, p. 427)

b) Advérbio sempre, quando adjungido a TP, rompe a adjacência entre o sujeito pré-verbal e o verbo:

(53) O Paulo sempre compra os pães. (PB)

(Silva, loc.cit.)

c) Advérbios com leitura orientada para o sujeito não podem romper a adjacência entre o sujeito deslocado à esquerda e o pronome resumptivo em construções de tópicos marcados:

(54) a. A Maria, tenho certeza de que ela intencionalmente derrubou o livro no chão.

b. *?A Maria, tenho certeza de que intencionalmente ela derrubou o livro no chão.

d) Advérbios com leitura orientada para o sujeito e o advérbio sempre não podem romper a adjacência entre o DP sujeito e o pronome resumptivo nas construções com duplicação do sujeito ${ }^{22}$ em $\mathrm{PB}$ :

(55) a. O João ele intencionalmente/sempre beijou a Maria. ${ }^{2.3}$

b. *? O João intencionalmentel sempre ele beijou a Maria.

Com base nas análises acima, chego a concluir que a hipótese de que todos os sujeitos pré-verbais em PB estão deslocados à

22 Conforme verificam Costa e Galves (2002), construções com duplicação do sujeito é um contexto marcado em orações raízes e agramaticais em contextos encaixados no PE, ao contrário do PB.

23 Agradeço a alguns falantes nativos do PB por me fornecerem seus julgamentos de gramaticalidade. 
esquerda torna-se problemática. Em geral, sujeitos pré-verbais ocupam a mesma posição-A no PB e no PE: Spec, AgrSP, salvo os casos das construções de tópicos sujeitos no PB e das construções de tópicos marcados nas duas línguas não analisadas neste artigo ${ }^{24}$..

\section{Conclusão}

A posição dos sujeitos sofre implicações da natureza de AGR no PB e no PE: o PE, por ser uma língua de sujeito nulo "prototípica", em virtude de possuir todas as propriedades listadas por Rizzi (1997), possui sujeitos pré-verbais em Spec, AgrSP e sujeitos pós-verbais em Spec, VP. Já no PB, os sujeitos sempre ocupam a posição pré-verbal, o que a assemelha a línguas como o francês, o inglês e o caboverdiano em que a inversão sujeito-verbo encontra-se submetida às construções inacusativas (cf. Kato, 1999, Berlinck, 1988, 2000, Coelho, 2000, Spanó, 2002, dentre outros). Contudo, embora o PB compartilhe com as três línguas mencionadas a possibilidade de só possuir inversão sujeito-verbo em construções inacusativas, ela assemelha-se ao PE pelo fato de DPs definidos e indefinidos ocuparem a posição pósverbal que, segundo observado por Barbosa (1996), é uma das propriedades das línguas de sujeito nulo, o que corrobora, mais uma vez, o caráter semi-pro-drop do PB.

Partindo da análise desenvolvida na seção 3, é plausível assumir que os sujeitos pré-verbais não estão deslocados à esquerda no $\mathrm{PB}$ e no $\mathrm{PE}$ e que o movimento do verbo é curto em ambas as línguas, estando aqueles ocupando a posição-A Spec, AgrSP, a posição mais alta da frase.

24 Para uma análise minuciosa das construções de tópicos marcados, ver Duarte (1987). 


\section{Referências}

ABNEY, S. P. The English noun phrase in its sentencial aspect. MIT Working Papers in Linguistics. Cambridge, Mass.: MIT Press, 1987.

ALEXIADOU, A.; ANAGNOSTOPOULOU, E. Parametrizing AGR: Word Order, V-movement and EPP-cheking. Natural Language and Linguistic Theory, n. 16, p. 491-539, 1998.

AMBAR, M. M. Para uma Sintaxe da Inversão Sujeito-Verbo em português. Tese (Doutorado em Lingüística). Lisboa: Faculdade de Letras, Universidade de Lisboa, 1992

BARBOSA, P. A new look at the null subject parameter. In: COSTA, J. et al. (Eds.). Proceedings of ConSOLE IV. Leiden, nov. 1996, p. 375-395.

BARBOSA, P. et. al. A Distribuição do Sujeito Nulo no Português Europeu e no Português Brasileiro. In: CORREIA, C. N.; GONÇALVES, A. Actas do XVI Encontro Nacional da Associação Portuguesa de Lingüística. Lisboa: Colibri Artes Gráficas, 2001, p. 539-550.

BELLETTI, A. The Case of Unaccusatives, Linguistic Inquiry, 19:1, p. 1-34, 1988.

BERLINCK, A. A ordem VSN no português do Brasil: sincronia e diacronia. Dissertação de Mestrado. Campinas: UNICAMP, 1988.

BERLINCK, A. Brazilian Portuguese VS Order: a Diachronic Analysis. In: KATO, M. A.; NEGRÃO, E. V. (Eds.). Brazilian Portuguese and the Null Subject Parameter. Madrid: Iberoamericana, 2000.

BRITO, A. M. Clause Structure, Subject Positions and Verb Movement about the Positions of sempre in European Portuguese and Brazilian Portuguese. In: D'HULST, Y. et al. (Eds.). Current Issues in Linguistic Theory. Amsterdam, Philadelphia: Jonh Benjamins Publishing Company, 2001, p. 63-85.

BRITO, A. M. et al. Estrutura da Frase Simples e Tipos de Frases. In: MATEUS, M. H. M. et al. Gramática da língua portuguesa. 5. ed. ver. aum. Lisboa : Caminho, 2003, p. 433-506. 
BURZIO, L. Italian Syntax. A Government-Binding Approach. Dordrecht, Reidel (atual Kluwer Academic), Publishing Company, 1986.

CHOMSKY, N. Lectures on Government and Binding. Dordrecht : Foris, 1981.

COELHO, I. L. A ordem VDP em construções monoargumentais: uma Restrição Sintático-Semântica. Tese (Doutorado em Lingüística). Florianópolis: Universidade Federal de Santa Catarina, 2000.

COELHO, I. L. Ordem VS e sujeito nulo em PE e PB. Apresentação no $2^{0}$ Colóquio do Projeto PE/ PB. Fortaleza: Universidade do Ceará,. 2001.

COSTA, J. Word Order Variation: A Constraint-based Approach. Holanda: Holland Academic Graphics, 1998.

COSTA, J. O comportamento de sujeitos e complementos em português europeu. Maceió: Ufal, 2000.

COSTA, J. Postverbal Subjects and Agreement in Unaccusative Contexts in European Portuguese. The Linguistic Review, 18, p. 1-17, 2001.

COSTA, J. Null vs Overt Spec, TP in European Portuguese. In: QUER J. et alii (Eds.). Romance Languages and Linguistic Theory 2001: Selacted papers from 'Going Romance'. Amsterdam : John Benjamins, 2003. p. 33-49.

COSTA, J. Syntactic outputs and interfaces. Paper presented in the $14^{\text {th }}$ Colloquium on Generative Grammar. Porto, April-2004, p. 1-8.

COSTA, J.; GALVES, C. External Subjects in Two Varieties of Portuguese Evidence for a Non-Unified Analysis. In: BEYSSADE, C. et al. Romance Languages and Linguistic Theory 2000, Utrecht, 30 November-2 December. v. 232. Amsterdam, Philadelphia: John Benjamins Publishing Company, 2002. p. 109-125.

COSTA, J.; FIGUEIREDO SILVA, M. C. Nominal and Verbal Agreement in Portuguese: an Argument for Distributed Morphology. Lisboa, 2002, p. 1-35. 
DUARTE, I. A construção de topicalização na gramática do português: regência e ligação e condições sobre movimento. 1987. Tese (Doutorado em Lingüística). Lisboa, Universidade de Lisboa, 1987.

DUARTE, M. E. L. The Loss of the 'Avoid Pronoum' Principle in Brazilian Portuguese. In: KATO, M. A.; NEGRÃO, E. V. (Eds.). Brazilian Portuguese and the Null Subject Parameter. Madrid: Iberoamericana, 2000, p. 17-36.

FIÉIS, M. A. Ordem de palavras, transitividade e inacusatividade: reflexão teórica e análise do português dos Séculos XIII a XVI. Tese (Doutorado em Linguística). Lisboa: Universidade Nova de Lisboa, 2003.

FIGUEIREDO SILVA, M. C. A posição sujeito no português brasileiro: Frases Finitas e Infinitivas. Campinas: Unicamp, 1996.

GALVES, C. O enfraquecimento da concordância no português brasileiro. In: ROBERTS, I.; KATO, M. A (Org.). Português brasileiro: uma viagem diacrônica. 2. ed. Campinas: Unicamp, 1996, p. 387-408.

GALVES, C.. Tópicos, Sujeitos, Pronomes e Concordância no Português Brasileiro. Cadernos de Estudos Lingiuísticos, n. 47, p. 1931, Jan./Jun. 1998.

GALVES, C. Ensaios Sobre as Gramáticas do Português. Campinas: UNICAMP, 2001.

GONÇALVES, M. F. H. S. L. Para uma redefinição do parâmetro do sujeito nulo. Dissertação (Mestrado em Lingüística Portuguesa Descritiva). Lisboa: Faculdade de Letras da Universidade de Lisboa, 1994.

HUANG, C. T. Logical Relations in Chinese and the Theory of Grammar. Dissertação Ph. D. MIT, 1982.

JAEGGLI, O.; SAFIR, K. J. The Null Subject Parameter and Parametric Theory. In: JAEGGLI, O.; SAFIR, K. J. The Null Subject Parameter. Kluwer Academic Publishers, p. 1-44, 1989. 


\section{PORTUGUÊS EUROPEU: IMPLICAÇŌES DA NATUREZA DE AGR}

KATO, M. A. A restrição de monoargumentalidade da ordem VS no português do Brasil. Fórum Linguiústico. Florianópolis: UFSC, Pósgraduação em Linguiística, p. 1-21, 1999 (no prelo).

KOOPMAN, H.; SPORTICHE, D. The position of subjects. Lingua, v. 85 , n. 2, p. 211-258, 1991.

OUHALLA, J. Functional Categories and Parametric Variation. London: Koutledge, 1991.

POLLOCK, J. Verb Movement, Universal Grammar, and the Structure of IP. Linguistic Inquiry, 20:3, p. 365-424, 1989.

PRATAS, F. Expletive pro and Overt Verbal Agreement Morphology: (Conter)Evidence from Capeverdean. In: $14^{\text {th }}$ Colloquium on Generative Grammar 2004. Porto. Handout..., 2004, p. 1-14.

RAPOSO, E. P. Teoria da gramática: A Faculdade da Linguagem. Lisboa: Caminho, 1992.

RIZZI, L. The New Comparative Syntax: Principles and Parameters of Universal Grammar. In: 10th ADVANCED COURSE "LANGUAGE AND COGNITION". Foundation Archives Jean Piaget, Geneva, p. 120, October 10, 1988.

RIZZI, L. A Parametric Approach to Comparative Syntax: Properties on the Pronominal System. In: HAEGEMAN, L. (Ed.). The New Comparative Syntax. London, New York: Longman, 1997, p. 268-285.

ROBERTS, I. Verbs and Diachronic Syntax. Dordrecht, Kluwer, 1993.

SPANÓ, M. A ordem VSN em construções monoargumentais na fala culta do português brasileiro e europeu. Dissertação (Mestrado em Língua Portuguesa). Rio de Janeiro: Universidade Federal do Rio de Janeiro, 2002.

SILVA, C. R. T. As implicações da natureza de AGR para a ordem VS: um estudo comparativo entre o português brasileiro e o português europeu. Tese (Doutorado em Linguística). Maceió, Universidade Federal de Alagoas, 2004. 
TORRES MORAES, M. A. C. R. Aspectos diacrônicos do movimento do verbo, estrutura da frase e o caso nominativo no português do Brasil. In: ROBERTS, I.; KATO, M. A. (Org.). Português brasileiro: uma viagem diacrônica. 2. ed. Campinas: Unicamp, 1996, p. 263-306. VIKNER, S. $\mathrm{V}^{\circ}$-to- $\mathrm{I}^{\circ}$ Movement and Inflection for Person in All Tenses. In: HAEGEMAN, L. (Ed.). The New Comparative Syntax. London, New York: Longman, 1997, p. 189-213. 